\title{
Systematic Review about Personal Growth Initiative
}

\author{
Clarissa Pinto Pizarro de Freitas ${ }^{1 *}$, Bruno Figueiredo Damásioº ${ }^{2}$ Patricia Renovato Tobo ${ }^{3}$, \\ Helder Hiroki Kamei ${ }^{3}$ and Sílvia Helena Koller ${ }^{4}$
}

\author{
${ }^{1}$ Post-Graduate Program in Psychology of the Salgado de Oliveira University (UNIVERSO) (Brasil). \\ ${ }^{2}$ Institute of Psychology of the Federal University of Rio de Janeiro (UFRJ) (Brasil). \\ ${ }^{3}$ Natura Innovation - Advanced Research in Sciences of Wellbeing (Brasil). \\ ${ }_{4}$ Post-Graduate Program in Psychology of the Federal University of Rio Grande do Sul (UFRGS) and Coordinator of Center of Psychological Studies - CEP-Rua (Brasil).
}

\begin{abstract}
Título: Revisión Sistemática sobre Iniciativa de Crecimiento Personal.
Resumen: El presente estudio busca realizar una revisión sistemática de publicaciones acerca de la iniciativa de crecimiento personal. Se realizó una revisión de literatura en las bases de datos Bireme, Index Psi, LILACS, PePSIC, Pubmed - Publisher's Medline, Wiley Online Library, PsycINFO, OneFile, SciVerse ScienceDirect, ERIC, Emerald Journals, PsycARTICLES - American Psychological Association, Directory of Open Access Journals DOAJ, SAGE Journals, SpringerLink, PLoS, IngentaConnect, IEEE Journals \& Magazines y SciELO. La revisión de la literatura se realizó a partir de diciembre de 2014 a enero de 2015, sin estipular límites de fecha para la publicación de los artículos. De los 53 estudios hallados, se excluyeron 7 y se analizaron 46. Los estudios se enfocaron en investigar las propiedades psicométricas de la escala iniciativa de crecimiento personal y de iniciativa de crecimiento personal escala II. Las relaciones de crecimiento personal iniciativa y otros constructos también fueron evaluados. Además, los estudios investigaron el impacto de las intervenciones para promover la iniciativa de crecimiento personal. Los resultados de estos estudios mostraron que iniciativa de crecimiento personal se relaciona positivamente con los niveles de bienestar, la autoestima y otras dimensiones positivas, y negativamente con la ansiedad, depresión y otros factores negativos.
\end{abstract}

Palabras clave: Iniciativa de crecimiento personal; evaluación; bienestar; revisión de literature.

\section{Introduction}

Throughout life, individuals are likely to experience challenging, adverse situations that require changes in the way they interact with others and handle various quotidian situations. Changes developed by people can be caused by external factors (e.g., job promotion) or can be changes caused by the individual (e.g., completing a post-graduate course). These changes may require those involved to adapt to a new context, interact with others differently, and use appropriate coping strategies to manage these new demands (Robitschek, 1997).

The process of change intentionally developed by individuals are recognized as personal growth initiative (PGI). Personal growth initiative can be understood as the active and intentional involvement of the individual in their personal growth process (Robitschek, 1998). Personal changes originating from PGI can be realized in the different life domains of individuals, occurring in the affective, cognitive and behavioral dimensions (Robitschek, 2003). Thus, the ability to identify and make personal changes that promote the positive development of individuals, when their living conditions change (e.g., birth of a child, job promotions,

* Dirección para correspondencia [Correspondence address]: Clarissa Pinto Pizarro de Freitas. Rua Ramiro Barcelos, 2600/104. CEP: 90035-003, Porto Alegre, RS (Brasil). E-mail: freitas.cpp@gmail.com
Abstract: The present study aimed to realize a systematic review of publications about personal growth initiative. A literature review was realized in Bireme, Index Psi, LILACS, PePSIC, Pubmed - Publisher's Medline, Wiley Online Library, PsycINFO, OneFile, SciVerse ScienceDirect, ERIC, Emerald Journals, PsycARTICLES - American Psychological Association, Directory of Open Access Journals - DOAJ, SAGE Journals, SpringerLink, PLoS, IngentaConnect, IEEE Journals \& Magazines and SciELO databases. The literature review was performed from December of 2014 to January of 2015, without stipulating date limits for the publication of the articles. It was found 53 studies, excluded seven, and analyzed 46 researches. The studies aimed to investigate the psychometric properties of personal growth initiative scale and personal growth initiative scale II. The relations of personal initiative growth and others constructs were also evaluated. Furthermore the studies investigated the impact of interventions to promote personal growth initiative. Results of these studies showed that personal growth initiative was positively related to levels of well-being, selfesteem and others positive dimensions, and negatively to anxiety, depression and others negative factors.

Key words: Personal growth initiative; assessment; well-being; literature review.

marriage), constitutes personal growth initiative (Robitschek, 1998).

Personal growth initiative comprises one of the dimensions of psychological well-being (Ryff \& Keyes, 1995). Psychological well-being refers to positive or optimal psychological functioning, composed of the dimensions selfacceptance, positive relations with others, autonomy, environment mastery, purpose in life, and personal growth (Ryff \& Keyes, 1995; Villacieros, Serrano, Bermejo, Magaña, \& Carabias, 2014). In addition to composing a dimension of psychological well-being (Ryff \& Keyes, 1995), PGI can be comprehended as a personal resource, as it encompasses a set of skills that contribute to making changes that promote positive development in people (Weigold \& Robitschek, 2011). Personal resources can be comprehended as the skills and positive evaluations of the individual regarding their ability to control and produce an impact on their environment. These resources are intrinsic and are characterized as independent dimensions, which are not fixed, can be developed and are influenced by changes in the environment. Thus, PGI as a personal resource refers to the individual skills that promote the development of intentional personal changes, consciously planned by the people who perform them (Weigold, Porfeli, \& Weigold, 2013; Weigold \& Robitschek, 2011).

The intentionality and consciousness present in the PGI processes are the characteristics that differentiate it from processes of unintended and unconscious personal changes 
(Robitschek, 1998; Weigold et al., 2013a). The processes of personal change can be categorized as unconscious and unintentional processes, conscious and unintentional processes, and conscious and intentional processes, such as PGI (Robitschek, 1998).

The processes of unconscious and unintentional change and of conscious and unintentional change usually result from environmental pressures, which also enable personal growth, although this is not intentional. In the process of unconscious and unintentional change, subjects may not be aware of what motivated their personal changes, or how they chose to assume new forms of interaction with other people. In the process of conscious and unintentional change individuals recognize the need for change, however have little control over how this process of change occurs (Robitschek, 1999). The distinction between unintended conscious and unconscious processes and PGI is important, as the processes of unintentional personal growth are negatively related to people's indices of well-being and to their positive development. The PGI process, in turn, is positively associated with increased levels of well-being and to the positive development of individuals (Robitschek, 1999).

In order to investigate PGI, Robitschek (1998) developed the Personal Growth Initiative Scale (PGIS). The development of this questionnaire was conducted with a sample of participants of a PGI promotion course. The PGIS presented an unidimensional structure, composed of nine items that evaluate personal growth through a six-point Likert scale, ranging from definitely disagree to definitely agree. The instrument presented satisfactory psychometric properties (Robitschek, 1998).

Despite the adequate factor structure, temporal stability, and convergent validity of the PGIS, this instrument does not investigate the different dimensions of PGI (e.g., cognitive and behavioral). As a result, Robitschek et al. (2012) developed the Personal Growth Initiative Scale - II (PGISII), which constituted a new multifactorial version of the PGIS. The PGIS-II consists of 16 items, divided into the following four factors: readiness for change; planfulness; intentional behavior; and using resources.

According to the proposition of Robitschek et al. (2012), PGI is composed of a cognitive dimension, recognized in the "Readiness for change" and "Planfulness" factors, and a behavioral dimension, identified in the "Using Resources" and "Intentional Behavior" factors. The "Readiness for Change" refers to the ability of the individual to identify or create situations with the potential to promote personal growth. The "planfulness" factor can be comprehended as a person's ability to organize strategies to facilitate their personal development. The "Intentional Behavior" factor, in turn, evaluates the disposition and personal motivation to achieve the goals established for personal change. The "Using Resources" factor covers the use of personal and external resources (e.g. help from others) in the promotion of personal growth (Robitschek et al., 2012). This is the only factor of PGI that encompasses the interpersonal dimension of individuals, which relates differently with the other factors of PGI (Robitschek et al., 2012; Weigold et al., 2013a).

Individuals who have high levels of the readiness for change, planfulness, intentional behavior, and using resources dimensions of PGI may have a greater potential to identify or create opportunities that enable and intensify their positive personal development (Robitschek \& Kashubeck, 1999). People with high levels of PGI adapt better to different situations, overcome stressful situations, have higher levels of life satisfaction, and seek appropriate solutions to the situations faced (Loo, Tsai, Raylu, \& Oei, 2014; Robitschek et al., 2012; Weigold et al., 2013a). High PGI indices are also positively related to positive affect and negatively to anxiety, depression and negative affect (Hardin et al., 2007; Robitschek \& Kashubeck, 1999; Robitschek \& Keyes, 2009).

A lack of PGI skills is associated with a negative impact in people's lives. It has been observed that low levels of PGI are related to difficulties in adapting to new contexts, so that those involved experience higher levels of stress and anxiety and lower levels of life satisfaction (Stevic \& Ward, 2008; Weigold \& Robitschek, 2011; Yakunina, Weigold, \& Weigold, 2013; Yakunina, Weigold, Weigold, Hercegovac, \& Elsayed, 2013). Difficulties in identifying opportunities for personal growth are also associated with the adoption of ineffective coping strategies, such as the prevalent use of emotion-focused coping strategies rather than the use of problem-focused strategies (Weigold \& Robitschek, 2011).

The positive impact of PGI on the levels of well-being experienced by people, as well as its role in positive development, exposes the relevance of comprehending this construct in depth. For this reason, a systematic literature review was performed, with the aim of analyzing studies that investigate the relationship of PGI with other psychological variables, as well as the instruments used to evaluate PGI.

\section{Method}

A systematic literature review related to the PGI concept was performed, without stipulating date limits. A total of 19 databases were consulted (Bireme, Index Psi, LILACS, PePSIC, Pubmed - Publisher's Medline, Wiley Online Library, PsycINFO, OneFile, SciVerse ScienceDirect, ERIC, Emerald Journals, PsycARTICLES - American Psychological Association, Directory of Open Access Journals - DOAJ, SAGE Journals, SpringerLink, PLoS, IngentaConnect, IEEE Journals \& Magazines, and SciELO), present in the CAPES Journals portal. The descriptor used in the search was "personal growth initiative" in English, Portuguese (iniciativa ao crescimento pessoal), and Spanish (iniciativa para el crecimiento personal). The descriptor had to be present in the abstract or body of the text. The study selection criteria were: empirical study; published in a peer-reviewed journal; and written in Portuguese, English or Spanish. No literature review studies were included in this search, since the aim of 
this study was to find scales and empirical studies about PGI. Similarly, studies published in books, book chapters, dissertations and theses were not included, due to the possible difficulties in accessing the material in its entirety. All procedures cited above were realized from December of 2014 to January of 2015.

\section{Results}

A total of 53 studies were encountered, seven were eliminated, and 46 studies involving the PGI construct were analyzed. Among the seven studies eliminated one referred to a book and the other six to dissertations and theses. The 46 articles encountered were published in English. There was an increase in publications over time, especially since 2007 (see Figure 1). The full references of the included studies are highlighted with an asterisk $(*)$ in the reference list.

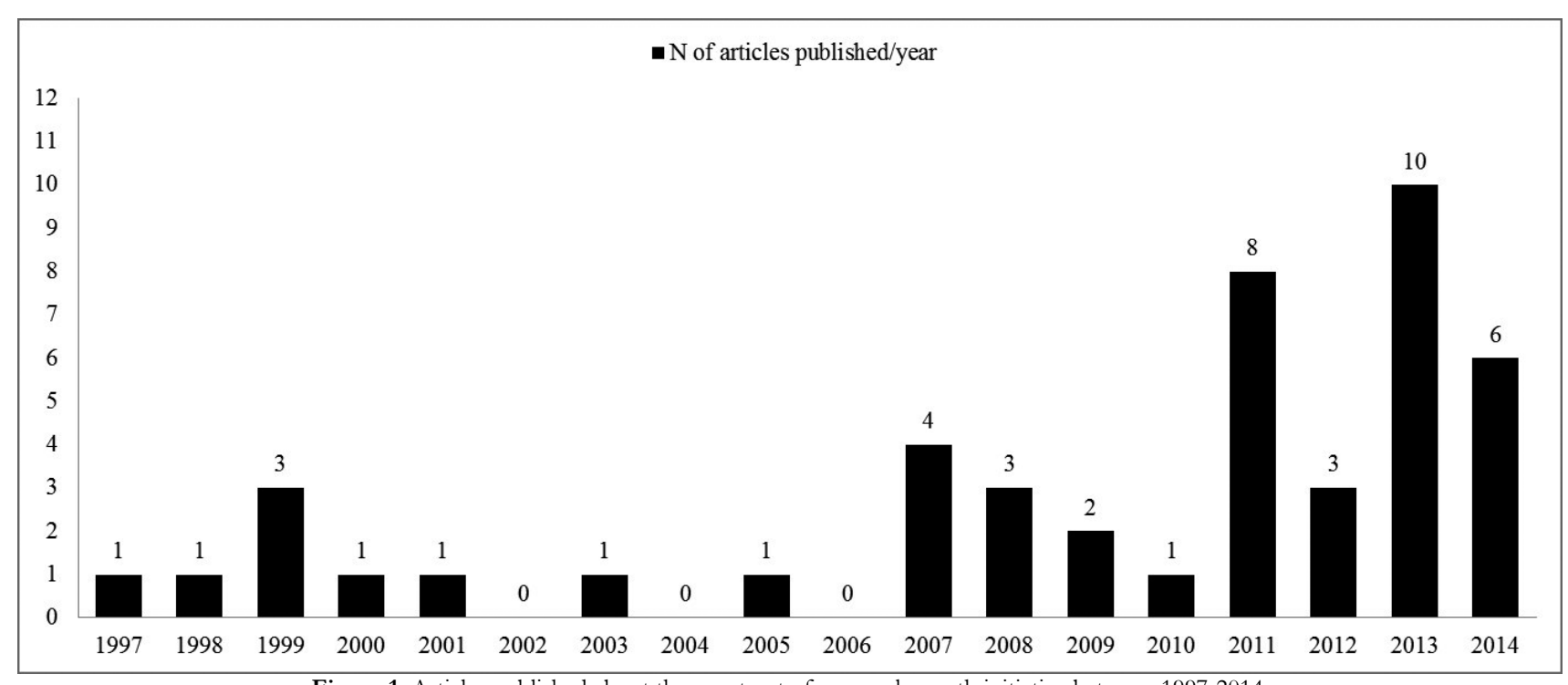

Figure 1. Articles published about the construct of personal growth initiative between 1997-2014.

Among the studies, nine investigated the psychometric properties of the scales used to evaluate PGI, two of which used the PGIS and seven the PGIS-II. The relationships of PGI with external variables were the focus of 34 studies, of which 28 used the PGIS, five applied the PGIS-II, and one was a qualitative study. Finally, three studies used PGI to verify the impact of interventions (see Table 1). In order to detail these results, these topics and the studies that comprise them, are shown separately.

Table 1. Characteristics of the articles analyzed.

\begin{tabular}{|c|c|c|c|}
\hline Authors /Year of Publication & Instrument & Sample & Country \\
\hline Robitschek, 1997 & PGIS & General Population & USA \\
\hline Robitschek, 1998 & PGIS & General Population & USA \\
\hline Robitschek, 1999 & PGIS & College Students & USA \\
\hline Robitschek \& Cook, 1999 & PGIS & College Students & USA \\
\hline Robitschek \& Kashubeck, 1999 & PGIS & College Students & USA \\
\hline Bartley \& Robitschek, 2000 & PGIS & College Students & USA \\
\hline Whittaker \& Robitschek, 2001 & PGIS & College Students & USA \\
\hline Robitschek, 2003 & PGIS & College Students & USA \\
\hline Robitschek \& Hershberger, 2005 & PGIS & General Population & USA \\
\hline Hardin, Weigold, Robitschek, \& Nixon, 2007 & PGIS & College Students & USA \\
\hline Neff, Rude, \& Kirkpatrick, 2007 & PGIS & College Students & USA \\
\hline Ogunyemi \& Mabekoje, 2007 & PGIS & College Students & Nigeria \\
\hline Shorey, Little, Snyder, Kluck, \& Robitschek, 2007 & PGIS & College Students & USA \\
\hline Kashubeck-West \& Meyer, 2008 & PGIS & General Population & USA \\
\hline
\end{tabular}


Table 1. Characteristics of the articles analyzed (continuation).

\begin{tabular}{|c|c|c|c|}
\hline Authors /Year of Publication & Instrument & Sample & Country \\
\hline Klockner \& Hicks, 2008 & PGIS & General Population & USA \\
\hline Stevic \& Ward, 2008 & PGIS & College Students & USA \\
\hline Borja \& Callahan, 2009 & PGIS & College Students & USA \\
\hline Robitschek \& Keyes, 2009 & PGIS & College Students & USA \\
\hline Negovan, 2010 & PGIS & College Students & Romania \\
\hline Barak \& Achiron, 2011 & PGIS & \multicolumn{2}{|c|}{$\begin{array}{l}\text { Patients with Multiple Sclerosis and Individu-Israel } \\
\text { als Not Diagnosed for Multiple Sclerosis }\end{array}$} \\
\hline Ivtzan, Chan, Gardner \& Prashar, 2011 & PGIS & College Students & England \\
\hline Oluyinka, 2011 & PGIS & College Students & Nigeria \\
\hline Sharma, Garg, \& Rastogi, 2011 & PGIS & College Students & India \\
\hline Sultan, 2011 & PGIS & $\begin{array}{l}\text { Patients Diagnosed with Depression and I } \\
\text { tients Diagnosed with Diabetes }\end{array}$ & a-Pakistan \\
\hline Vaingankar et al., 2011 & PGIS & General Population & Singapore \\
\hline Wang \& Tien, 2011 & PGIS & Workers & China \\
\hline Weigold \& Robitschek, 2011 & PGIS & College Students & USA \\
\hline Ayub \& Iqbal, 2012 & PGIS & College Students & Pakistan \\
\hline Lasun \& Odufowokan, 2012 & PGIS & Workers & Nigeria \\
\hline Robitschek et al., 2012 & PGIS & General Population & USA \\
\hline Bhattacharya \& Mehrotra, 2013 & Semi-structured interview & College Students & India \\
\hline Sharma \& Rani, 2013 & PGIS - II & College Students & India \\
\hline Thoen \& Robitschek, 2013 & PGIS - II & College Students & USA \\
\hline Weigold et al., 2013a & PGIS - II & College Students & USA \\
\hline Weigold, Weigold \& Russell, 2013 & PGIS - II & College Students & USA \\
\hline Yakunina et al., 2013a & PGIS - II & College Students & USA \\
\hline Yakunina et al., 2013b & PGIS - II & College Students & USA \\
\hline Yalcin \& Malkoc, 2013 & PGIS - II & College Students & Turkey \\
\hline Callahan, Borja, Herbert, Maxwell, \& Ruggero, 2013 & PGIS & College Students & Romania \\
\hline Negovan \& Bogdan, 2013 & PGIS & College Students & USA \\
\hline Bhattacharya \& Mehrotra, 2014 & PGIS - II & College Students & India \\
\hline Loo et al., 2014 & PGIS & General Population & China \\
\hline Luyckx \& Robitschek, 2014 & PGIS - II & College Students & Belgium \\
\hline Sharma \& Rani, 2014 & PGIS - II & College Students & India \\
\hline Weigold, Weigold, Russell, \& Drakeford, 2014 & PGIS - II & College Students & USA \\
\hline Yang \& Chang, 2014 & PGIS - II & College Students & China \\
\hline
\end{tabular}

Psychometric Properties of the Personal Growth Initiative Scale (PGIS) and the Personal Growth Initiative Scale II (PGIS-II)

The Personal Growth Initiative Scale (PGIS) was the first scale developed to evaluate PGI (Robitschek, 1998, 2003). This scale presents nine items in a unidimensional structure (Robitschek, 1998). The development study of the PGIS involved a sample of participants of a PGI promotion course. The final version of PGIS presented adequate internal consistency $(a=.90)$ and fit indices for the unidimensional structure $\left(\chi^{2}(27)=61.5, p<.001, \mathrm{CFI}=.95, \mathrm{NFI}=\right.$ .93). Furthermore, the PGIS showed a test-retest reliability index of .74 after a period of two months (Robitschek, 1998).

Although the PGIS presented stability in the test-retest reliability evaluations with the North-American sample investigated by Robitschek (1998), the unidimensional structure of the PGIS was not observed in a sample of Mexican university students (Robitschek, 2003). The psychometric properties of the PGIS were evaluated among Mexican university students, due to cultural differences between the
European-American culture (i.e., individualist) and the Hispanic culture (i.e. collectivist) (Allik, \& Realo, 2004). In this study, it was shown that the PGIS, when applied in Hispanic populations, presented improvement in the model fit indices when proposing a two-factor structure, compared to the unidimensional structure (Robitschek, 2003).

The Personal Growth Initiative Scale - II (PGIS-II) was developed in order to overcome the limitation of the PGIS in evaluating the multifactorial construct of PGI through a single-factor structure (Robitschek et al., 2012). The PGIS-II has 16 items, organized in the four factors that constitute PGI. The development study of the PGIS-II was conducted with a sample of psychology students.

The factor structure of the PGIS-II showed adequate fit indices s-b $\chi^{2}(330, n=1.796)=1356.70, p<0.001 ;$ SRMR $=$ 0.09 ; $\mathrm{RMSEA}=0.07$ (90\% C.I. $=0.07-0.08)$. In addition satisfactory test-retest stability indices were observed, ranging from 0.73 (using resources) to 0.81 (planfulness) (Robitschek et al., 2012). Despite the four-factor structure providing the best fit indices, the authors propose that the general PGI score can be obtained through the sum of the 
four dimensions that compose the PGIS-II (Robitschek et al., 2012).

The study by Yakunina et al. (2013a) aimed to investigate the psychometric properties of the North-American version of the PGIS-II in a non-native population of the United States of America (USA). Non-native students of the USA attending North-American Universities were interviewed (Yakunina et al., 2013a). The findings corroborate the universality of the construct, as well as the comprehension of the four-factor construct of PGI (readiness for change, planfulness, intentional behavior, and using resources). The fourfactor structure of the PGIS-II presented adequate fit indices $\left(\chi^{2}(98, n=386)=353.22, p<0.001 ; \mathrm{CFI}=0.93\right.$; SRMR $=0.05 ;$ RMSEA $=0.08$ ) (Yakunina et al., 2013a).

Another study that examined the psychometric properties of the PGIS-II in the USA verified the invariance of the scale regarding data collection methods. The results of data collected through paper and pencil questionnaires and through internet based questionnaires were compared (Weigold et al., 2013b). The findings of this study demonstrate the invariance of the PGIS-II in pen and paper and virtual collection methods, indicating that the two forms of data collection are effective for the evaluation of PGI (Weigold et al., 2013b).

Yang and Chang (2014) conducted an adaptation study for the Chinese version of the PGIS-II. In this study a sample of Chinese university students was analyzed. It was observed that the version of PGIS-II adapted to Mandarin presented adequate fit indices for the four-factor version $\left(\chi^{2}\right.$ $(98, n=927)=816.90, p<0.001 ; \mathrm{CFI}=0.95$; SRMR $=$ 0.06; RMSEA $=0.07(90 \%$ C.I. $=0.07-0.08))$. The testretest stability indices were also adequate, ranging from 0.70 (readiness for change) to 0.90 (using resources). These results demonstrate that the PGIS-II is an adequate instrument to evaluate PGI in the Chinese culture (Yang \& Chang, 2014).

The Turkish version of the PGIS-II was adapted based on a sample of university students (Yalcin \& Malkoc, 2013). It was observed that, despite the differences in social values between the Turkish and American cultures, the four PGI factors were identified. The structure of the Turkish version of the PGIS-II was similar to that observed in the original scale, and the fit indices were adequate $\left(\chi^{2}(98, n=279)=\right.$ $220.49, p<0.001$; $\mathrm{CFI}=0.98$; SRMR $=0.14$; RMSEA $=$ 0.06) (Yalcin \& Malkoc, 2013).

Unlike that observed in the samples of non-native people residing in the USA (Yakunina et al., 2013a), Chinese (Yang \& Chang, 2014) and Turks (Yalcin \& Malkoc, 2013), the Indian version of the PGIS-II presented a different factor structure to the original (Bhattacharya \& Mehrotra, 2014). The investigation of the psychometric properties of the PGIS-II was performed by Bhattacharya and Mehrotra (2014). The study sample was comprised of university students. The analysis of the Indian version of the PGIS-II showed that the four PGI factors presented unsatisfactory internal consistency indices in the sample studied. As a re- sult, the structure of the scale was examined through exploratory factor analysis. The analysis results showed that the Indian version of the PGIS-II had a two-factor structure. The first factor refers to the cognitive aspects of PGI, identified as "Awareness of the need for change", which presented adequate internal consistency $(\alpha=0.86)$. The second factor covers the behavioral aspects of PGI, denominated "Acting on the awareness", with satisfactory internal consistency $(\alpha=0.79)$. The four PGI factors proposed in the original scale (Robitschek et al., 2012) were not replicated in this Indian sample. However, the results of this study on PGI in an Indian sample confirm the universality of the construct, since the cognitive and behavioral aspects of PGI were identified (Bhattacharya \& Mehrotra, 2014).

\section{Personal Growth Initiative and Relationships with External Variables}

Due to the awareness and intentionality of PGI being central characteristics of this process of personal change, Robitschek (1999) investigated how PGI was related to other personal growth processes. For this, the author analyzed the associations of PGI with the unconscious and unintentional growth process, with the conscious and unintentionally growth process, and with intentional ways of growing in a sample of university students. The results showed that PGI was related negatively to the unconscious and unintentional growth process and to the conscious and unintentional growth process, and positively to intentional ways of growing (Robitschek, 1999), demonstrating that PGI is a developmental process deliberated by the individual.

In other studies, it was observed that PGI presented positive relationships with positive characteristics of the individual, e.g. self-esteem (Kashubeck-West \& Meyer, 2008); self-efficacy (Ogunyemi \& Mabekoje, 2007); and selfcompassion (Neff et al., 2007). Similarly, PGI was negatively associated with negative personal characteristics, such as increased chances of developing a pathological gambling disorder (Loo et al., 2014).

Personal growth initiative was positively related to the dimensions of self-acceptance, positive relations with others, autonomy, environment mastery, purpose in life, and personal growth of the psychological well-being (Ayub \& Iqbal, 2012; Kashubeck-West \& Meyer, 2008; Robitschek \& Kashubeck, 1999; Robitschek \& Keyes, 2009). Studies that investigated psychological well-being as a single-factor dimension also evidenced the positive relationship between this and PGI (Kashubeck-West \& Meyer, 2008; Lasun \& Odufowokan, 2012; Negovan, 2010; Robitschek, 1999; Shorey et al., 2007)

Higher levels of PGI were associated with the presence of higher indices of emotional well-being, social well-being (Negovan, 2010) happiness, social actualization, social contribution, social coherence, social integration (Robitschek \& Keyes, 2009), life satisfaction (Kashubeck-West \& Meyer, 2008; Robitschek \& Kashubeck, 1999; Robitschek \& Keyes, 
2009; Stevic \& Ward, 2008); positive mental health (Ogunyemi \& Mabekoje, 2007; Vaingankar et al., 2011); and positive affect (Hardin et al., 2007; Robitschek \& Keyes, 2009). Consequently, people who had higher levels of PGI were more likely to possess lower levels of negative affect (Hardin et al., 2007), stress (Hardin et al., 2007; Shorey et al., 2007), lower levels of perceived stigma (Sultan, 2011) and more chance of healthily recovering from traumatic experiences (Borja \& Callahan, 2009; Callahan et al., 2013).

The characteristics of the family system of individuals may be related to the PGI indices (Robitschek \& Kashubeck, 1999; Whittaker \& Robitschek, 2001). Regarding the family system in a sample of North-American university students, it was demonstrated that family cohesion and communication were positively related to PGI, whereas family conflict was negatively related to this variable. It was also observed that PGI mediates the relationships between the family processes ant the levels of stress experienced by individuals (Robitschek \& Kashubeck, 1999). In another NorthAmerican study (Whittaker \& Robitschek, 2001), it was observed that among women the family processes and the encouragement of personal development in the family system were positively associated with PGI. Among men, the family processes and family organization were positively associated with PGI.

Personality characteristics may also have an impact on the PGI indices (Sharma et al., 2011). In a sample of Indian students it was observed that the dimensions that compose the type A personality (tension, impatience, restlessness, directed toward achievement, centralization of tasks, and addiction to work) were positively related to PGI, while the dimensions of the type B personality (compliance, casualness, passivity, relaxation and patience) presented a negative association with PGI (Sharma et al., 2011).

In addition to the aforementioned relationships, it was demonstrated that PGI was positively associated with greater career exploration, clarity regarding the vocational identity (Bartley \& Robitschek, 2000; Robitschek \& Cook, 1999), and spirituality (Ivtzan et al., 2011). It has been observed that the presentation of some behaviors that may contribute to the development of the individual is associated with higher levels of PGI, such as the effective use of adaptive coping strategies (e.g., problem-focused coping, Weigold \& Robitschek, 2011), choosing to engage in psychotherapeutic treatments (Klockner \& Hicks, 2008; Oluyinka, 2011), as well as the commitment to the psychotherapy process performed (Robitschek \& Hershberger, 2005) and the tendency to develop behaviors out of the individual's comfort zone (Lasun \& Odufowokan, 2012; Ogunyemi \& Mabekoje, 2007).

In order to comprehend the phenomenon of PGI in different groups, studies compared the PGI indices of multiple sclerosis patients with those of people without multiple sclerosis (Barak \& Achiron, 2011) and students of public universities with those of private universities, and classroom based undergraduate students with distance based undergraduate students (Negovan \& Bogdan, 2013). In these studies it was observed that the groups (patients vs. healthy, public university students vs. private university students, classroom based undergraduate students vs. distance based undergraduate students) did not show differences in relation to the PGI indices (Barak \& Achiron, 2011; Negovan \& Bogdan, 2013).

Only five studies used the PGIS-II as an instrument to evaluate PGI (Luyckx \& Robitschek, 2014; Sharma \& Rani, 2013, 2014; Weigold et al., 2014; Yakunina et al., 2013a). The use of the PGIS-II allows the investigation of the cognitive (openness to change and planfulness) and behavioral (using resources and intentional behavior) dimensions of PGI through a multifactorial scale (Robitschek et al., 2012). Futhermore, Robitschek et al. (2012) proposed that the sum of the scores of the four factors provide an overall PGI score.

In a study using the PGIS-II with North-American university students, it was shown that the dimensions readiness for change, planfulness and intentional behavior were positively associated with the original measure of PGI, selfefficacy, internal locus of control and negatively associated with powerful others locus of control and chance locus of control. However, the using resources dimension did not show the same relationship pattern as the other PGI factors, in a way that using resources was positively associated with the original measure of PGI and self-efficacy only (Weigold et al., 2014).

Studies developed with Indian university students used the PGIS-II to evaluate how the four dimensions of PGI were associated with variables related to well-being (Sharma \& Rani, 2013, 2014). It was shown that the four PGI dimensions (readiness for change, planfulness, using resources, and intentional behavior) presented positive relationships with self-efficacy dimensions (initiative, persistence and effort) (Sharma \& Rani, 2013), emotional well-being, psychological well-being and social well-being (Sharma \& Rani, 2014).

The study by Luyckx and Robitschek (2014) with NorthAmerican youths showed that the PGI dimensions are related to the processes of identity (exploration in breadth, exploration in depth, ruminative exploration, commitment making, and identification with commitment) and to the levels of depression and self-esteem of the participants. The exploration process refers to active questioning regarding the identity and the search for experiences of different social roles, which precedes the commitment process. In the exploration in breadth process the young person broadly analyses and experiences the different social roles. Exploration in depth is characterized by a process in which the young person is intensely involved in the analysis of their personal values and their social role. Ruminative exploration refers to a process of continual exploration, associated with anxiety and depression, in which the young person has difficulty committing to choices that will enable the development of their identity. The process of commitment making is constituted by the beliefs, goals and values that young people adopt as part of their identity. Identification with commitment can be comprehended as how young people identify 
with the social groups and activities that share the same values and social goals adopted by them (Luyckx \& Robitschek, 2014).

The readiness for change dimension was positively related to the identity process of ruminative exploration. The planfulness dimension was positively associated with selfesteem, and the processes of commitment making and identification with commitment, and negatively associated with ruminative exploration and depression. Using resources was positively associated with exploration in depth and ruminative exploration. The intentional behavior dimension was positively related to exploration in breadth and exploration in depth. Furthermore, the exploration in breadth identity process totally mediated the relationship of the readiness for change dimension with the indices of self-esteem and depression. The ruminative exploration identity process partially mediated the relationship of using resources and intentional behavior with self-esteem and depression. Finally, the processes of exploration in breadth and ruminative exploration partially mediated the relationships of planfulness with the levels of self-esteem and depression (Luyckx \& Robitschek, 2014).

Studies by Sharma and Rani $(2013,2014)$ and Yakunina et al. (2013b) investigated the relationship between the overall PGI score, evaluated through the PGIS-II, and other variables. These studies demonstrated that the overall PGI score was positively related to hardiness, universal-diverse orientation, psychological adjustment, emotional well-being, psychological well-being and social well-being, self-efficacy and negatively related to stress (Sharma \& Rani, 2013; Yakunina et al., 2013b).

The results cited above showed that PGI and its dimensions (readiness for change, planfulness, using resources, and intentional behavior) are related to several external variables. In social sciences, the magnitude of correlations may be classified as small when values $(r)$ are smaller than .30 , medium when values range from .30 to .50 , and large when values are higher than .50 (Cohen, 1992). The present study showed that the general score of PGIS presented high positive correlations with personal resources (e.g. self-esteem, autonomy, Kashubeck-West \& Meyer, 2008), futureoriented variables (e.g. purpose in life, Ayub \& Iqbal, 2012), and well-being (e.g. psychological well-being, Robitschek, 1999). The positive relations of medium magnitude between PGI and external variables covered mainly well-being related constructs (e.g. happiness, Robitschek \& Keyes, 2009) and personal resoucers (e.g. self-compassion, Neff et al., 2007). The positive correlations of PGI with low magnitude were in general with social well-being related variables, such as social actualization and social integration (Robitschek \& Keyes, 2009). The PGI general score negative relations were of high magnitude with future-oriented variables (e.g. unconscious and unintentional growth process, Robitschek, 1999) and medium with variables related to mental health, such as anxiety (Weigold \& Robitschek, 2011) and stress (Hardin et al., 2007) (See Table 2).

The PGI dimensions (readiness for change, planfulness, using resources, and intentional behavior) were positively and higly associated with personal resources, like selfefficacy (Weigold et al., 2014). The PGI dimensions presented positive and moderate correlations with variables related to personal growth (e.g. exploration in breadth and in depth, Luyckx \& Robitschek, 2014). Furthermore, results showed that the readiness for change, planfulness, using resources, and intentional behavior presented positive associations of low magnitude with well-being related constructs, such as psychological, social and emotional well-being (Sharma \& Rani, 2014). The negative relations between PGI dimensions and external variables presented low magnitude, as can be observed betwen depressive symptons and ruminative exploration (Luyckx \& Robitschek, 2014) (See Table 2).

The PGI general score assessed by the PGIS-II showed positive high correlations with personal features, such as hardiness and universal-diverse orientation (Yakunina et al., 2013b). The relations of PGI general score to well-being were low (e.g. psychological, social and emotional well-being, Sharma \& Rani, 2014). Moreover, the negative relations of PGI general score to negative outcomes were medium, such as the relation of PGI to stress (Yakunina et al., 2013b) (see Table 2).

Table 2. Relations of Personal Growth Initiative (readiness for change, planfulness, intentional behavior, and using resources) with external variables.

\begin{tabular}{|c|c|c|c|c|c|c|c|}
\hline & \multirow[b]{2}{*}{ Authors /Year of Publication } & \multirow{2}{*}{$\frac{\text { PGIS }}{\text { GS }}$} & \multicolumn{5}{|c|}{ PGIS - II } \\
\hline & & & $\mathrm{RC}$ & $\mathrm{Pla}$ & IB & UR & GS \\
\hline $\mathrm{UU}$ & Robitschek, 1999 & $-.54 *$ & & & & & \\
\hline $\mathrm{CU}$ & Robitschek, 1999 & $-.25 *$ & & & & & \\
\hline IWG & Robitschek, 1999 & $.34 *$ & & & & & \\
\hline ICL & Weigold et al., 2014 & & $.33^{*}$ & $.40^{*}$ & .08 & $.38 *$ & \\
\hline PLC & Weigold et al., 2014 & & $-.27 *$ & $-.26^{*}$ & .04 & $-.19 *$ & \\
\hline CLC & Weigold et al., 2014 & & $-.24 *$ & $-.28^{*}$ & .08 & $-.24 *$ & \\
\hline \multirow[t]{2}{*}{ SE } & Kashubeck-West \& Meyer, 2008 & $.65^{*}$ & & & & & \\
\hline & Luyckx \& Robitschek, 2014 & & $.20^{*}$ & $.33^{*}$ & $.18^{*}$ & $.24 *$ & \\
\hline \multirow[t]{2}{*}{ SEf } & Ogunyemi \& Mabekoje, 2007 & $.22^{*}$ & & & & & \\
\hline & Weigold et al., 2014 & & $.65^{*}$ & $.70^{*}$ & $.26^{*}$ & $.66^{*}$ & \\
\hline Ini & Sharma \& Rani, 2013 & & $-.11 *$ & $-.19 *$ & $.11 *$ & $-.20 *$ & $-.15^{*}$ \\
\hline Per & Sharma \& Rani, 2013 & & $.14 *$ & $.12 *$ & $.10^{*}$ & $.14 *$ & $.18^{*}$ \\
\hline
\end{tabular}




\begin{tabular}{|c|c|c|c|c|c|c|c|}
\hline & \multirow[b]{2}{*}{ Authors / Year of Publication } & \multirow{2}{*}{$\begin{array}{c}\text { PGIS } \\
\text { GS }\end{array}$} & \multicolumn{5}{|c|}{ PGIS - II } \\
\hline & & & $\mathrm{RC}$ & Pla & IB & UR & GS \\
\hline Ef & Sharma \& Rani, 2013 & & $.17 *$ & $.30^{*}$ & $.10^{*}$ & $.33^{*}$ & $.33^{*}$ \\
\hline SC & Neff et al., 2007 & $.45^{*}$ & & & & & \\
\hline \multirow[t]{2}{*}{ BCZ } & Lasun \& Odufowokan, 2012 & $.25^{*}$ & & & & & \\
\hline & Ogunyemi \& Mabekoje, 2007 & $.26^{*}$ & & & & & \\
\hline PGIS & Weigold et al., 2014 & & $.61 *$ & $.69^{*}$ & $.35^{*}$ & $.68^{*}$ & \\
\hline $\mathrm{H}$ & Yakunina et al., 2013b & & & & & & $.50^{*}$ \\
\hline UDO & Yakunina et al., 2013b & & & & & & $.38 *$ \\
\hline TPA & Sharma et al., 2011 & $.61 *$ & & & & & \\
\hline ТРB & Sharma et al., 2011 & $-.37 *$ & & & & & \\
\hline \multirow[t]{3}{*}{ LS } & Kashubeck-West \& Meyer, 2008 & $.52^{*}$ & & & & & \\
\hline & Robitschek \& Kashubeck, 1999 & .42 & & & & & \\
\hline & Robitschek \& Keyes, 2009 & $.40^{*}$ to $.36^{*}$ & & & & & \\
\hline \multirow[t]{2}{*}{ PA } & Robitschek \& Keyes, 2009 & $.38 *$ to $.37 *$ & & & & & \\
\hline & Hardin et al., 2007 & $.49 *$ & & & & & \\
\hline NA & Hardin et al., 2007 & $-.26^{*}$ & & & & & \\
\hline \multirow[t]{6}{*}{ PWB } & Kashubeck-West \& Meyer, 2008 & $.73^{*}$ & & & & & \\
\hline & Lasun \& Odufowokan, 2012 & $.11 *$ & & & & & \\
\hline & Negovan, 2010 & $.60^{*}$ & & & & & \\
\hline & Robitschek, 1999 & $.70^{*}$ & & & & & \\
\hline & Sharma \& Rani, 2014 & & $.18^{*}$ & $.29 *$ & .03 & $.35^{*}$ & $.31 *$ \\
\hline & Shorey et al., 2007 & $.31 *$ to $.42 *$ & & & & & \\
\hline \multirow[t]{4}{*}{$\mathrm{Au}$} & Ayub \& Iqbal, 2012 & $.22^{*}$ & & & & & \\
\hline & Kashubeck-West \& Meyer, 2008 & $.56^{*}$ & & & & & \\
\hline & Negovan \& Bogdan, 2013 & $.43^{*}$ & & & & & \\
\hline & Robitschek \& Keyes, 2009 & $.28^{*}$ to $.42 *$ & & & & & \\
\hline \multirow[t]{3}{*}{ EM } & Ayub \& Iqbal, 2012 & $.34 *$ & & & & & \\
\hline & Kashubeck-West \& Meyer, 2008 & $.61 *$ & & & & & \\
\hline & Robitschek \& Keyes, 2009 & $.41 *$ to $.46^{*}$ & & & & & \\
\hline \multirow[t]{4}{*}{ PRO } & Ayub \& Iqbal, 2012 & $.24^{*}$ & & & & & \\
\hline & Kashubeck-West \& Meyer, 2008 & $.56^{*}$ & & & & & \\
\hline & Robitschek \& Kashubeck, 1999 & $.39 *$ & & & & & \\
\hline & Robitschek \& Keyes, 2009 & $.32 *$ to $.33^{*}$ & & & & & \\
\hline \multirow[t]{3}{*}{ PL } & Ayub \& Iqbal, 2012 & $.56^{*}$ & & & & & \\
\hline & Kashubeck-West \& Meyer, 2008 & $.65^{*}$ & & & & & \\
\hline & Robitschek \& Keyes, 2009 & $.39 *$ to $.35 *$ & & & & & \\
\hline \multirow[t]{4}{*}{ PG } & Ayub \& Iqbal, 2012 & $.48^{*}$ & & & & & \\
\hline & Kashubeck-West \& Meyer, 2008 & $.59 *$ & & & & & \\
\hline & Robitschek \& Kashubeck, 1999 & $.43^{*}$ & & & & & \\
\hline & Robitschek \& Keyes, 2009 & $.38 *$ to $.33 *$ & & & & & \\
\hline \multirow[t]{4}{*}{ SA } & Ayub \& Iqbal, 2012 & $.54 *$ & & & & & \\
\hline & Kashubeck-West \& Meyer, 2008 & $.62^{*}$ & & & & & \\
\hline & Robitschek \& Kashubeck, 1999 & $.51 *$ & & & & & \\
\hline & Robitschek \& Keyes, 2009 & $.41 *$ to $.41 *$ & & & & & \\
\hline \multirow[t]{2}{*}{ EWB } & Sharma \& Rani, 2014 & & $.10^{*}$ & $.15^{*}$ & .02 & $.17 *$ & $.16^{*}$ \\
\hline & Negovan, 2010 & $.30^{*}$ & & & & & \\
\hline Hap & Robitschek \& Keyes, 2009 & $.41 *$ to $.36^{*}$ & & & & & \\
\hline SWB & Sharma \& Rani, 2014 & & $.10^{*}$ & $.10^{*}$ & -.05 & $.17 *$ & .13 \\
\hline SAc & Robitschek \& Keyes, 2009 & $.26^{*}$ & & & & & \\
\hline SCon & Robitschek \& Keyes, 2009 & $.31 *$ to $.40^{*}$ & & & & & \\
\hline SCoh & Robitschek \& Keyes, 2009 & $.35^{*}$ to $.36^{*}$ & & & & & \\
\hline SInt & Robitschek \& Keyes, 2009 & $.28^{*}$ & & & & & \\
\hline PMH & Ogunyemi \& Mabekoje, 2007 & $.11 *$ & & & & & \\
\hline & Vaingankar et al., 2011 & $.63^{*}$ & & & & & \\
\hline PsAd & Yakunina et al., 2013b & & & & & & $.60^{*}$ \\
\hline $\mathrm{CM}$ & Luyckx \& Robitschek, 2014 & & $.20^{*}$ & $.28^{*}$ & $.14^{*}$ & $.22^{*}$ & \\
\hline IWC & Luyckx \& Robitschek, 2014 & & $.33^{*}$ & $.42^{*}$ & $.20^{*}$ & $.30^{*}$ & \\
\hline EB & Luyckx \& Robitschek, 2014 & & $.30^{*}$ & $.29^{*}$ & $.19^{*}$ & $.34^{*}$ & \\
\hline ED & Luyckx \& Robitschek, 2014 & & $.33^{*}$ & $.35^{*}$ & $.32^{*}$ & $.39 *$ & \\
\hline RE & Luyckx \& Robitschek, 2014 & & -.05 & $-.20 *$ & .02 & -.07 & \\
\hline FP & Whittaker \& Robitschek, 2001 & $.25^{*}$ to $.29 *$ & & & & & \\
\hline
\end{tabular}


Table 2. Relations of Personal Growth Initiative (readiness for change, planfulness, intentional behavior, and using resources) with external variables (continuation).

\begin{tabular}{|c|c|c|c|c|c|c|c|}
\hline & & \multirow{2}{*}{$\begin{array}{c}\text { PGIS } \\
\text { GS }\end{array}$} & \multicolumn{5}{|c|}{ PGIS - II } \\
\hline & & & $\mathrm{RC}$ & $\mathrm{Pla}$ & IB & UR & GS \\
\hline $\mathrm{O}$ & Whittaker \& Robitschek, 2001 & $.15^{*}$ to $.20^{*}$ & & & & & \\
\hline \multirow[t]{2}{*}{$\mathrm{CE}$} & Bartley \& Robitschek, 2000 & $.41 *$ & & & & & \\
\hline & Robitschek \& Cook, 1999 & $.39 *$ & & & & & \\
\hline \multirow[t]{2}{*}{ VI } & Bartley \& Robitschek, 2000 & $.38^{*}$ to $.55^{*}$ & & & & & \\
\hline & Robitschek \& Cook, 1999 & $.43 *$ to $.52^{*}$ & & & & & \\
\hline Sp & Ivtzan et al., 2011 & $.33 *$ & & & & & \\
\hline PFC & Weigold \& Robitschek, 2011 & $.39 *$ to $.49 *$ & & & & & \\
\hline $\mathrm{EFC}$ & Weigold \& Robitschek, 2011 & $-.25^{*}$ to $-.34^{*}$ & & & & & \\
\hline PSt & Sultan,2011 & $-.63^{*}$ & & & & & \\
\hline GD & Loo et al., 2014 & $.12 *$ & & & & & \\
\hline \multirow[t]{2}{*}{ An } & Robitschek \& Kashubeck, 1999 & $-.27 *$ & & & & & \\
\hline & Weigold \& Robitschek, 2011 & $-.27 *$ to $-.36 *$ & & & & & \\
\hline \multirow[t]{2}{*}{ DS } & Luyckx \& Robitschek, 2014 & & $-.15^{*}$ & $-.27 *$ & $-.09 *$ & $-.16^{*}$ & \\
\hline & Robitschek \& Kashubeck, 1999 & $-.29 *$ & & & & & \\
\hline \multirow[t]{3}{*}{ S } & Hardin et al., 2007 & $-.40^{*}$ & & & & & \\
\hline & Shorey et al., 2007 & $-.20 *$ to $-.29 *$ & & & & & \\
\hline & Yakunina et al., 2013b & & & & & & $-.44 *$ \\
\hline \multirow[t]{2}{*}{ TS } & Borja \& Callahan, 2009 & $-.13^{*}$ & & & & & \\
\hline & Callahan et al., 2013 & $-.24 *$ & & & & & \\
\hline
\end{tabular}

Note: $* p<.05$, PGIS = Personal Growth Initiative Scale, PGIS-II = Personal Growth Initiative Scale - II, GS = General Score, RC $=$ Readiness for Change, $\mathrm{Pla}=$ Planfulness, $\mathrm{IB}=$ Intentional Behavior, and UR $=$ Using Resources, $\mathrm{UU}=$ Unconscious and Unintentional Growth Process, $\mathrm{CU}=\mathrm{Conscious}$ and Unintentional Growth Process, IWG = Intentional Ways of Growing, ICL = Internal Locus of Control, PLC = Powerful Others Locus of Control, CLC = Chance Locus of Control, $\mathrm{SE}=$ self-esteem, SEf $=$ self-efficacy, Ini = Initiative, Per $=$ Persistence, Ef $=$ Effort, $\mathrm{SC}=\mathrm{Self}-\mathrm{Compassion}, \mathrm{TBCZ}=\mathrm{Tendency}$ to Develop Behaviors Out of the Individual's Comfort Zone, $\mathrm{H}=$ Hardiness, UDO $=$ Universal-Diverse Orientation, TPA $=$ Type A Personality, TBP $=$ Type B Personality, LS = Life Satisfaction, PA = Positive Affect, NA = Negative Affect, PWB = Psychological Well-Being, Au = Autonomy, EM = Environment Mastery, PRO = Positive Relations with Others, PL = Purpose in Life, PG = Personal Growth, SA = Self-Acceptance, EWB = Emotional WellBeing, Hap $=$ Happiness, SWB $=$ Social Well-Being, SAc $=$ Social Actualization, SCon $=$ Social Contribution, SCoh $=$ Social Coherence, SInt $=$ Social Integration, $\mathrm{PMH}=$ Positive Mental Health, PsAd = Psychological Adjustment, $\mathrm{CM}=$ Commitment Making, IWC = Identification with Commitment, EB = Exploration in Breadth, ED = Exploration in Depth, RE = Ruminative Exploration, FP = Family Process, $\mathrm{O}=\mathrm{Organization}, \mathrm{CE}=\mathrm{Career}$ Exploration, VI $=$ Vocational Identity, $\mathrm{Sp}=$ Spirituality, PFC $=$ Problem-Focused Coping, EFC $=$ Emotion-Focused Coping; PSt $=$ Perceived Stigma, GD = Gambling Disorder, An = Anxiety, DS = Depressive Symptoms, S = Stress, TS = Trauma Severity.

\section{Qualitative Evaluation of Personal Growth Initiative}

Only one study was found that qualitatively evaluated the relationships of the PGI phenomenon (Bhattacharya \& Mehrotra, 2013). In this study, interviews were conducted with two focus groups of university students, in order to investigate the relationships of PGI with the individual's perceptions of their identity, development of personal change, and goals established. It was observed that PGI was associated with the university students' positive perceptions of their identity, consciously making beneficial personal changes, and with the achievement of the goals established by them. The findings of this study highlighted the role of PGI in making personal changes and developing selfevaluations congruent to the identity of the individual (Bhattacharya \& Mehrotra, 2013).

\section{Interventions for Personal Growth Initiative Promo- tion}

Personal growth initiative was also used as the outcome variable to investigate the impact of interventions designed to promote self-knowledge and the development of skills related to PGI (Robitschek, 1997; Thoen \& Robitschek, 2013; Wang \& Tien, 2011). The results of the studies presented below indicate that the interventions developed were effective in promoting the development of skills related to PGI (Robitschek, 1997; Thoen \& Robitschek, 2013; Wang \& Tien, 2011).

Robitschek (1997) developed an intervention consisting of a retreat lasting eight to 15 days, performed with participants of a self-knowledge course. The activities were carried out in groups and involved climbing, canoeing and excursions in the forest. The purpose of the retreat was to motivate the participants to recognize their limitations, to work in teams and to develop skills related to PGI. The impact of the intervention was evaluated through a quasi-experimental design, with only the intervention group being evaluated. Participants responded to questionnaires one month before the retreat, at its conclusion, and three months after the end of the retreat. Personal growth initiative was measured by means of the PGIS. It was shown that the intervention promoted an increase in the PGI indices, which remained stable three months after the end of the intervention (Robitschek, 1997). 
The intervention developed by Thoen and Robitschek (2013) was directed toward university students. In this study an experimental design was used to investigate the impact of the intervention. For this, the participants were randomly assigned to four conditions: a) psychoeducation regarding PGI and activities for personal growth; b) reading of a text about storms and activities for personal growth; psychoeducation regarding PGI and family activity; c) reading a text about storms and family activity (Thoen \& Robitschek, 2013). The four conditions of the intervention were individually developed over the course of one week. Participants completed the questionnaires at the beginning and end of the study, with the period of one week between the applications. The overall score of the PGIS-II was used to investigate the PGI indices. It was observed that the condition that combined psychoeducation regarding PGI and the development of activities for personal growth was the most effective in promoting skills related to PGI (Thoen \& Robitschek, 2013).

Wang and Tien (2011) conducted an intervention to promote PGI among professionals working in the areas of health, education, commerce, and industry. An experimental design was used to investigate the impact of the intervention. Participants were randomly selected to participate in an intervention to promote PGI, which was composed of six to eight sessions, or to participate in one or two sessions of career guidance (Wang \& Tien, 2011). Participants responded to questionnaires only after participating in the interventions. The PGIS was applied to investigate the PGI indices. The intervention developed by Wang and Tien (2011) was effective for the development of PGI.

\section{Discussion}

In the present study it was demonstrated that studies about PGI have shown a gradual increase since the 1990s, at which time Robitschek (1997) initiated the systematic study of PGI and developed the PGIS (Robitschek, 1998) This growth has been most notable in the last eight years (2007-2014), the period in which $80.4 \%$ of the publications are condensed (see Figure 1).

The studies found in this systematic review focused on investigating the psychometric properties of the instruments used to evaluate PGI, relations between PGI and other variables related to well-being, and the impact of interventions that seek to promote PGI. It was observed that the population investigated in more than half of the studies published was the university student population (33 studies, 70\%), and that the majority of these studies were conducted in the USA (26 studies, 55\%) (See Table 1). These results suggest that the samples evaluated could present high levels of homogeneity. The homogeneity of the samples investigated in different studies regarding PGI can reduce the possibility of the findings being generalized to different contexts and populations, as well as the results being used to develop interventions that address the positive development of the participants. Furthermore, no studies were found that had been conducted in Latin America or Oceania. Thus, there is a need to investigate the PGI phenomenon in different contexts and locations.

The studies that investigated the psychometric properties of the PGIS showed that the scale did not present a stable structure. The lack of stability of the scale when used in different populations suggested the need to review the items that compose it, which motivated Robitschek to develop the revised version (PGIS-II) of the scale (Robitschek et al., 2012).

Regarding the studies that investigated the psychometric properties of the PGIS-II, these demonstrated the multifactorial structure of the scale, indicating the existence of the four constructs that compose PGI (Robitschek et al., 2012). The adaptation studies of the PGIS-II showed the stability of the four-factor structure in China (Yang \& Chang, 2014); the USA (Weigold et al., 2014; Yakunina et al., 2013a); and Turkey (Yalcin \& Malkoc, 2013).

The results of the study by Weigold et al. (2013) demonstrated that the structure of the North-American version of PGIS-II is invariant, even when different methods of data collection (pen and paper vs. online) are used. Analyzed jointly, the results of this study, coupled with the validity evidence of the multifactor structure of the PGIS-II (Robitschek et al., 2012; Weigold et al., 2014; Yakunina et al., 2013a; Yalcin \& Malkoc, 2013; Yang \& Chang, 2014) indicate the potential of the PGIS-II for use in evaluating PGI.

Despite the evidence for the stability of the multifactorial structure of the PGIS-II (Weigold et al., 2013b; Weigold et al., 2014; Yakunina et al., 2013; Yalcin \& Malkoc, 2013; Yang \& Chang, 2014), this structure was not observed in the Indian sample (Bhattacharya \& Mehrotra, 2014). The impossibility for Bhattacharya and Mehrotra (2014) to evidence the four-factor structure of the PGIS-II could be due to either instability in the scale, or specific cultural questions related to the Indiana culture. Therefore, other studies using the PGIS-II in different cultures are needed to evaluate the extent to which the PGIS-II can maintain its theoretically stipulated multifactorial structure in different contexts. If the results found by Bhattacharya and Mehrotra (2014) are replicate in future studies, it is possible that there is a need for sensitive items to be developed to evaluate the dimensions that compose PGI in different cultures.

In this review, some studies developed with the PGIS-II used the overall score to evaluate PGI (Sharma \& Rani, 2013, 2014; Thoen \& Robitschek, 2013; Yakunina et al., 2013b). The use of the overall score of the PGIS-II to evaluate PGI is a procedure recommended by Robitschek et al. (2012). However, in the studies that evaluated the structure of the PGIS-II (Robitschek et al., 2012; Weigold et al., 2014; Yakunina et al., 2013a; Yalcin \& Malkoc, 2013; Yang \& Chang, 2014) there was no evidence for the existence of an overall score being a factor greater than the four independent PGI dimensions. The absence of evidence to support 
the comprehension of an overall PGI score makes it impossible to use this as a general indicator of PGI. Thus, it is suggested that the results of the studies investigating the overall PGI score are carefully analyzed. Similarly, it is suggested that further studies evaluate the plausibility of the PGIS-II presenting a hierarchical structure, with a secondorder general factor (PGI).

Regarding the psychometric properties of the PGIS and PGIS-II and the use of the adapted versions, studies were found that used scales without citing whether the adaptation process of the scale was conducted (India, Sharma, \& Rani, 2013, 2014; Sharma et al., 2011; Israel, Barak \& Achiron, 2011; Nigeria, Lasun \& Odufowokan, 2012; Ogunyemi \& Mabekoje, 2007; Oluyinka, 2011; Pakistan, Ayub \& Iqbal, 2012; Romania, Negovan, 2010; Negovan \& Bogdan, 2013; Singapore, Vaingankar et al., 2011). The absence of unification of the findings has a negative impact on the comprehension of the PGI phenomenon. For example, in the studies in India, different versions of the PGIS-II were used (four-factor structure, Sharma \& Rani, 2013, 2014; Sharma et al., 2011; two-factor structure, Bhattacharya \& Mehrotra, 2014). The realization of the adaptation and the evaluation of the psychometric properties of an instrument are processes that are essential to demonstrate the reliability of the instrument used. The use of instruments that have not been adequately adapted and validated to the cultural context in which they are used limits the methodological quality of the study. Furthermore, this practice reduces the reliability and generalizability of the results encountered.

With regard to the relationship of PGI with external variables, PGI and its dimensions (readiness for change, planfulness, using resources, and intentional behavior) were positively associated with the variables related to a state of increased well-being (e.g., positive affect, and psychological, social and emotional well-being), and negatively related to factors associated with states of lower levels of well-being (e.g., stress, anxiety and depression). The relationship pattern of PGI and its dimensions with the variables evaluated in the studies cited in the present article show that PGI, in fact, appears as an aspect of the personal growth dimension of psychological well-being (Ryff \& Keyes, 1995).

The skills present in PGI are also associated with the person's ability to evaluate adverse and stressful situations as challenges and opportunities for personal growth, so that they experience lower levels of stress when coping with these situations (Weigold \& Robitschek, 2011; Yakunina et al., 2013b). Furthermore, readiness for change and using resources may intensify the individual's search for new experiences that contribute to their personal development. The possibility of experiencing a variety of situations enhances the chances of people strengthening their social and emotional support network, as well as experiencing positive situations more frequently compared to individuals with low PGI indices (Yakunina et al., 2013b). These relationships demonstrate the impact of the PGI skills on evaluations of the experiences faced by individuals, showing that PGI can also be comprehended as a personal resource.

The comprehension of PGI as a set of skills that can be developed was evident in the interventions that were effective in promoting PGI (Robitschek, 1997; Thoen \& Robitschek, 2013; Wang \& Tien, 2011). The use of PGI as the outcome variable also demonstrated the sensitivity of the PGIS (Robitschek, 1997; Wang and Tien, 2011) and PGIS-II (Robitschek \& Thoen, 2013) in evaluating changes in PGI levels over time.

Although this study provides important information about the PGI construct, it has its limitations. The language of the articles included was the main limitation of this review, since the review included only articles written in English, Spanish or Portuguese. This language limitation may restricted the acess for publications of others countries. This criterion was used to gain a better comprehension of the studies and to valorize those that can be accessed by the majority of researchers

Since the use of articles was limitated by the author language limitations, only articles written in Portuguese, Spanish or English were used.

This review contributes by presenting a comprehensive overview of studies on the PGI construct. Future researches should test the validity of the PGIS-II in different samples, such as with clinic patients, or across cultures. Moreover, longitudinal studies should be developed to assess the existence of causal relationships between PGI dimensions, personal features and well-being.

\section{Final Considerations}

Personal growth initiative is characterized by the skills of individuals to intentionally seek opportunities to mature and realize personal changes that will enable their positive development (Robitschek et al., 2012). The results of the studies analyzed in this review indicated that PGI plays a crucial role for individuals to experience increased levels of well-being, develop themselves positively and adapt to adverse situations.

It was also evidenced that PGI constitutes a personal resource. For example, in the study by Barak and Achiron (2011) no significant differences were observed between the levels of PGI among patients with multiple sclerosis and people who were not diagnosed with this syndrome. Furthermore, the potential was demonstrated for this personal resource to be promoted by interventions focused on the development of PGI related skills (Robitschek, 1997; Thoen \& Robitschek, 2013; Wang \& Tien, 2011).

The results of the studies mentioned above highlight the importance of developing effective intervetions for the development of PGI related skills as a strategy to promote higher levels of well-being, as well as expand the individuals' abilities to overcome adversities. Also, PGIS-II may be used to assess how personal growth dimensions act on the pro- 
cess of self-improvement. Theis would help researches and health professionals to identify to what extent cognitive and behavioral features impact in the positive development of individuals.

The universality of PGI was observed in studies performed in different contexts (Bhattacharya \& Mehrotra, 2014; Robitschek et al., 2012; Weigold et al., 2014; Yakunina et al., 2013a; Yalcin \& Malkoc, 2013; Yang \& Chang, 2014).

\section{References}

Allik, J., \& Realo, A. (2004). Individualism-Collectivism and Social Capital. Journal of Cross-Cultural Psychology, 35, 29-49. doi: $10.1177 / 0022022103260381$

* Ayub, N., \& Iqbal, S. (2012). The relationship of Personal Growth Initiative, Psychological Well-Being, and Psychological Distress among Adolescents. Journal of Teaching and Education, 1(6), 101-107.

* Barak, Y., \& Achiron, A. (2011). Happiness and Personal Growth are Attainable in Interferon-Beta-1a Treated Multiple Sclerosis Patients. Journal of Happiness Studies, 12(5), 887-895. doi:10.1007/s10902-0109234-6

* Bartley, D. F., \& Robitschek, C. (2000). Career Exploration: A Multivariate Analysis of Predictors. Journal of Vocational Behavior, 56(1), 63-81. doi:10.1006/jube.1999.1708

* Bhattacharya, A., \& Mehrotra, S. (2013). The Journey of Personal Growth: A Qualitative Exploration of Personal Growth Processes in Young Adulthood. Psychological Studies, 58(4), 456-463. doi:10.1007/s12646013-0222-x

* Bhattacharya, A., \& Mehrotra, S. (2014). Personal Growth Initiative Scale: How does it perform in Indian youth samples? Journal of the Indian Academy of Applied Psychology, 40(1), 122-129.

* Borja, S. E., \& Callahan, J. L. (2009). The Trauma Outcome Process Assessment Model: A Structural Equation Model Examination of Adjustment. Journal of Child Sexual Abuse, 18(5), 532-552. doi:10.1080/10538710903182685

* Callahan, J. L., Borja, S. E., Herbert, G. L., Maxwell, K., \& Ruggero, C. J. (2013). Test of the trauma outcome process assessment model: One model of individual and environmental factors to explain adjustment. Traumatology, 19(4), 268-279. doi:10.1177/1534765613476098

Cohen, J. (1992). A power primer. Psychological Bulletin, 112(1), 155-159. http://doi.org/10.1037/0033-2909.112.1.155

* Hardin, E. E., Weigold, I. K., Robitschek, C., \& Nixon, A. E. (2007). Selfdiscrepancy and distress: The role of personal growth initiative. Journal of Counseling Psychology, 54(1), 86-92. doi:10.1037/0022-0167.54.1.86

* Ivtzan, I., Chan, C. P. L., Gardner, H. E., \& Prashar, K. (2011). Linking Religion and Spirituality with Psychological Well-being: Examining Selfactualisation, Meaning in Life, and Personal Growth Initiative. Journal of Religion and Health, 52(3), 915-929. doi:10.1007/s10943-011-9540-2

* Kashubeck-West, S., \& Meyer, J. (2008). The well-being of women who are late deafened. Journal of Counseling Psychology, 55(4), 463-472. doi:10.1037/a0013619

* Klockner, K. D., \& Hicks, R. (2008). My next client: Understanding the Big Five and positive personality dispositions of those seeking psychosocial support interventions. International Coaching Psychology Review, 3, 148-163.

* Lasun, G., \& Odufowokan, B. A. (2012). Transformational effects of upgrading Nigerian Colleges of Education to Universities in the globalization era: A perspective of staff psychological well-being. Advances in Management \& Applied Economics, 2(1), 1792-7552.

* Loo, J. M. Y., Tsai, J.-S., Raylu, N., \& Oei, T. P. S. (2014). Gratitude, Hope, Mindfulness and Personal-Growth Initiative: Buffers or Risk Factors for Problem Gambling? Plos One, 9(2), e83889. doi:10.1371/journal.pone.0083889

* Luyckx, K., \& Robitschek, C. (2014). Personal growth initiative and identity formation in adolescence through young adulthood: Mediating processes on the pathway to well-being. Journal of Adolescence, 37(7), 973981. doi:10.1016/j.adolescence.2014.07.009
However, the limited range of the samples investigated and the non-use of the version of the PGIS-II adapted to the cultural context analyzed limited comprehension of the PGI phenomenon. Thus, there is a need to develop studies that evaluate the structure of the PGIS-II in different cultures, and that seek to investigate comprehensive samples, which include different groups present in the general population.

* Neff, K. D., Rude, S. S., \& Kirkpatrick, K. L. (2007). An examination of self-compassion in relation to positive psychological functioning and personality traits. Journal of Research in Personality, 41(4), 908-916. doi:10.1016/i.jrp.2006.08.002

* Negovan, V. (2010). Dimensions of students' psychosocial well-being and their measurement: Validation of a students' Psychosocial Well Being Inventory. Europe's Journal of Psychology, 6(2). doi:10.5964/ejop.v6i2.186

* Negovan, V., \& Bogdan, C. (2013). Learning Context and Undergraduate Students' Needs for Autonomy and Competence, Achievement Motivation and Personal Growth Initiative. Procedia - Social and Behavioral Sciences, 78, 300-304. doi:10.1016/j.sbspro.2013.04.299

* Ogunyemi, A. O., \& Mabekoje, S. O. (2007). Self-efficacy, risk-taking behavior and mental health as predictors of personal growth initiative among university undergraduates. Electronic Journal of Research in Educational Psychology, 5(2), 349-362.

* Oluyinka, O. (2011). Psychological predictors of attitude towards seeking professional psychological help in a Nigerian university student population. South African Journal of Psychology, 41(3), 310-327.

* Robitschek, C. (1998). Personal growth initiative: The construct and its measure. Measurement and Evaluation in Counseling and Development, 30, 183-198.

* Robitschek, C. (1999). Further validation of the Personal Growth Initiative Scale. Measurement and Evaluation in Counseling and Development, 31(4), 197210.

* Robitschek, C. (1997). Life/Career Renewal: An Intervention for Vocational and Other Life Transitions. Journal of Career Development, 24(2), 133-146.

* Robitschek, C. (2003). Validity of Personal Growth Initiative Scale scores with a Mexican American college student population. Journal of Counseling Psychology, 50(4), 496-502. doi:10.1037/0022-0167.50.4.496

* Robitschek, C., \& Kashubeck, S. (1999). A structural model of parental alcoholism, family functioning, and psychological health: The mediating effects of hardiness and personal growth orientation. Journal of Counseling Psychology, 46, 159-172.

* Robitschek, C., \& Hershberger, A. R. (2005). Predicting Expectations About Counseling: Psychological Factors and Gender Implications. Journal of Counseling \& Development, 83(4), 457-469. doi:10.1002/j.15566678.2005.tb00367.x

* Robitschek, C., \& Keyes, C. L. M. (2009). Keyes's model of mental health with personal growth initiative as a parsimonious predictor. Journal of Counseling Psychology, 56(2), 321-329. doi:10.1037/a0013954

* Robitschek, C., Ashton, M. W., Spering, C. C., Geiger, N., Byers, D., Schotts, G. C., \& Thoen, M. A. (2012). Development and psychometric evaluation of the Personal Growth Initiative Scale-II. Journal of Counseling Psychology, 59(2), 274-287. doi:10.1037/a0027310

Ryff, C. D., \& Keyes, C. L. M. (1995). The structure of psychological wellbeing revisited. Journal of Personality and Social Psychology, 69(4), 719-727. doi:10.1037/0022-3514.69.4.719

* Sharma, S. K., Garg, P., \& Rastogi, R. (2011). Personality as a Predictor of Personal Growth Initiative. The IUP Journal of Organizational Behavior, 10(3), 41-5.

* Sharma, S. K., \& Rani, R. (2013). Relationship of Personal Growth Initiative with Self-Efficacy among University Postgraduate Students. Journal of Education and Practice, 4(16), 125-135. 
* Sharma, S. K., \& Rani, R. (2014). Impact of Mental Health on Personal Growth Initiative (PGI) among University Postgraduates. Research on Humanities and Social Sciences, 4(3), 134-147.

* Shorey, H. S., Little, T. D., Snyder, C. R., Kluck, B., \& Robitschek, C. (2007). Hope and personal growth initiative: A comparison of positive, future-oriented constructs. Personality and Individual Differences, 43(7), 1917-1926. doi:10.1016/j.paid.2007.06.011

* Stevic, C. R., \& Ward, R. M. (2008). Initiating Personal Growth: The Role of Recognition and Life Satisfaction on the Development of College Students. Social Indicators Research, 89(3), 523-534. doi:10.1007/s11205008-9247-2

* Sultan, S. (2011). Stigmatization: Addressing Self-Esteem and Personal Growth in Patients with Psychological and Physiological Illness. Pakistan Journal of Social Sciences (PJSS), 31(1), 29-36.

* Thoen, M. A., \& Robitschek, C. (2013). Intentional Growth Training: Developing an Intervention to Increase Personal Growth Initiative: Intentional Growth Training. Applied Psychology: Health and Well-Being, 5(2), 149-170. doi:10.1111/aphw.12001

* Vaingankar, J., Subramaniam, M., Chong, S. A., Abdin, E., Orlando Edelen, M., Picco, L., Lim, Y. W., Phua, M. Y., Chua, B. Y., Tee, J. Y. S., \& Sherbourne, C. (2011). The positive mental health instrument: development and validation of a culturally relevant scale in a multiethnic asian population. Health and Quality of Life Outcomes, 9(1), 92. doi:10.1186/1477-7525-9-92

Villacieros, M., Serrano, I., Bermejo, J. C., Magaña, M., \& Carabias, R. (2014). Social support and psychological well-being as possible predictors of complicated grief in a cross-section of people in mourning. Anales de Psicología, 30(3). http://doi.org/10.6018/analesps.30.3.154691

* Wang, Y.-C., \& Tien, H.-L. S. (2011). The Effectiveness of the StrengthCentered Career Adjustment Model for Dual-Career Women in Taiwan. The Career Development Quarterly, 59(5), 467-479. doi:10.1002/j.21610045.2011.tb00972.x

* Weigold, A., Weigold, I. K., \& Russell, E. J. (2013b). Examination of the equivalence of self-report survey-based paper-and-pencil and internet data collection methods. Psychological Methods, 18(1), 53-70. doi:10.1037/a0031607

* Weigold, I. K., \& Robitschek, C. (2011). Agentic personality characteristics and coping: Their relation to trait anxiety in college students. American Journal of Orthopsychiatry, 81(2), 255-264. doi:10.1111/j.19390025.2011.01094.x

* Weigold, I. K., Porfeli, E. J., \& Weigold, A. (2013a). Examining tenets of personal growth initiative using the Personal Growth Initiative Scale-II. Psychological Assessment, 25(4), 1396-1403. doi:10.1037/a0034104

* Weigold, I. K., Weigold, A., Russell, E. J., \& Drakeford, N. M. (2014) Examination of the Psychometric Properties of the Personal Growth Initiative Scale-II in African American College Students. Assessment. doi:10.1177/1073191114524019

* Whittaker, A. E., \& Robitschek, C. (2001). Multidimensional family functioning as predictors of personal growth initiative. Journal of Counseling Psychology, 48, 420-427.

* Yakunina, E. S., Weigold, I. K., \& Weigold, A. (2013a). Personal growth initiative: Relations with acculturative stress and international student adjustment. International Perspectives in Psychology: Research, Practice, Consultation, 2(1), 62-71. doi:10.1037/a0030888

* Yakunina, E. S., Weigold, I. K., Weigold, A., Hercegovac, S., \& Elsayed, N. (2013b). International Students' Personal and Multicultural Strengths: Reducing Acculturative Stress and Promoting Adjustment. Journal of Counseling \& Development, 91(2), 216-223. doi:10.1002/j.15566676.2013.00088.x

* Yalçın, I. \& Malkoç, A. (2013). Adaptation of Personal Growth Initiative Scale- II to Turkish and investigation of psychometric properties. The Journal of Psychiatry and Neurological Sciences, 26 (3), 258-266.

* Yang, H., \& Chang, E. C. (2014). Examining the Structure, Reliability, and Validity of the Chinese Personal Growth Initiative Scale-II: Evidence for the Importance of Intentional Self-Change Among Chinese. Journal of Personality Assessment, 140228164555000. doi:10.1080/00223891.2014.886256

(Article received: 03-02-2015; revised: 22-05-2015; accepted: 31-07-2015 